\title{
SIGNIFICANCE OF EXTENSOR PLANTAR RESPONSES IN MUSCULAR DYSTROPHY
}

\author{
BY \\ MERVYN J. EADIE, JOHN H. TYRER and JOHN M. SUTHERLAND \\ From Medical Professorial and Neurological Units, Brisbane Hospital, Queensland, Australia
}

(RECEIVED FOR PUBLICATION JULY 11, 1962)

The absence of primary disease of the central nervous system is usually regarded as characteristic of the muscular dystrophies. However, there have been occasional reports of the presence of signs, generally accepted as indicating organic disease of the central nervous system, in otherwise typical examples of muscular dystrophy (Bell, 1943); these signs include extensor plantar responses which have been recorded on several occasions (Kollarits, 1906; Crouzon, 1911; Léri, Girot and Basch, 1923: Sjövall, 1936; Levison, 1951; Hassan and Mostafa. 1961).

A report is here given of a family in which each of four male siblings showed evidence of classical pseudohypertrophic muscular dystrophy and also bilateral extensor plantar responses; the significance of this association is discussed.

\section{Case Reports}

Four brothers aged 11 and 10 years, with twins aged 9 years (Cases 1, 2, 3 and 4 respectively), were referred for neurological opinion. Because of a family history of myopathy, which is discussed below, the mother had observed her children carefully for evidence of any abnormal features suggestive of this condition. She stated that each of her four sons showed an unnatural mobility of the ankles from birth. Each child began walking in the latter half of his second year of life. None had a normal gait, each walked on a wider base than normal, was prone to fall readily and had difficulty in negotiating stairs. The mother had noticed that each child tended to 'climb up his own legs' when trying to rise from the recumbent position. The muscular weakness gradually progressed so that Cases 1 and 2 had been unable to stand or walk since the age of 9 years.

The mother stated that of her seven sisters and six brothers, four brothers had died of muscular dystrophy before the age of 20 years, three of the latter having had "high arched feet'. One of her sisters had five sons, three of whom had died with muscular dystrophy by the age of 12 years (Fig. 1). The patients and their parents were born in Australia. There was no known history of muscular dystrophy or "high arched feet" in generations antecedent to the patients mother. though full details of the pedigree could not be traced owing to loss of records in Liechtenstein during World War II.

On examination, the four children appeared to be of normal intelligence. Cases 1 and 2 were unable to stand or walk, while Cases 3 and 4 walked with a high steppage', unstable gait. The plantar responses were unequivocally extensor in each patient; the neurological features of the family are summarized in the accompanying Table. In connexion with the plantar responses, it should be noted that in each child the power of voluntary plantar flexion of the great toes was greater than the power of voluntary dorsiflexion. None of our patients showed spinal deformity.

Blood Wassermann reactions were negative in all four children. Cerebrospinal fluid was examined in Cases 1 and 2 and was normal cytologically, biochemically and serologically. Electroencephalograms were normal in Cases 1 and 2, but Cases 3 and 4 showed a generalized slow wave activity slightly in excess of normal for the age. Electrocardiograms were normal in each child.

Muscle biopsies from the right gastrocnemius and right peroneus brevis muscles from Case 4 revealed features of muscular dystrophy (Fig. 2). There was gross variation in muscle fibre size, the larger fibres being in the gastrocnemius muscle. The muscles showed degenerative changes (chiefly hyaline changes and fragmentation) with phagocytosis and gross infiltration by fibro-fatty tissue. Intravital methylene blue staining (Ccërs and Woolf, 1959) showed that the intramuscular nerves appeared normal apart from a sinuous and oblique course, some with irregular degenerative swellings and some with finely-beaded sprouts. While many motor end-plates appeared normal, some showed degenerative changes and a few were enlarged.

\section{Discussion}

The presence of an extensor plantar response. in what is considered to be a primary disorder of muscle, is of interest. It is widely held that this response is a sign of underdeveloped or impaired function of the pyramidal tract (Brain and Wilkinson. 1959). Perusal of the literature since 1896 when Babinski first described the extensor plantar response shows that while the combination of muscular 

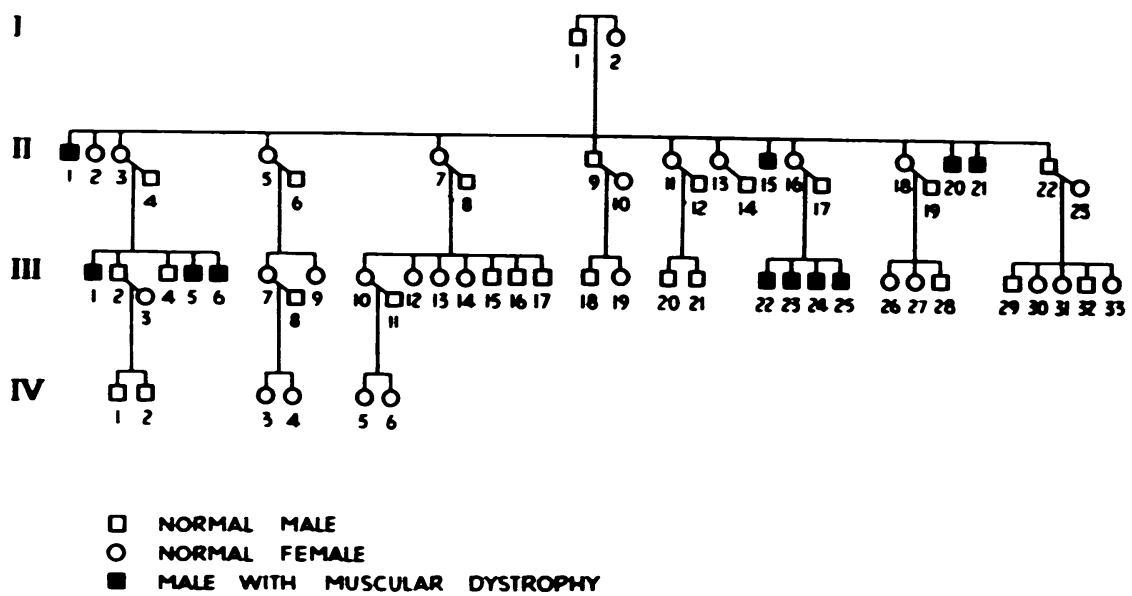

Fig. 1.-Family tree of the four patients here reported (Sibship III, Cases 22. 23. 24 and 25).

TABLE

RELEVANT CLINICAL FINDINGS IN FOUR MALE SIBLINGS WITH PSEUDOHYPERTROPHIC MUSCULAR DYSTROPHY

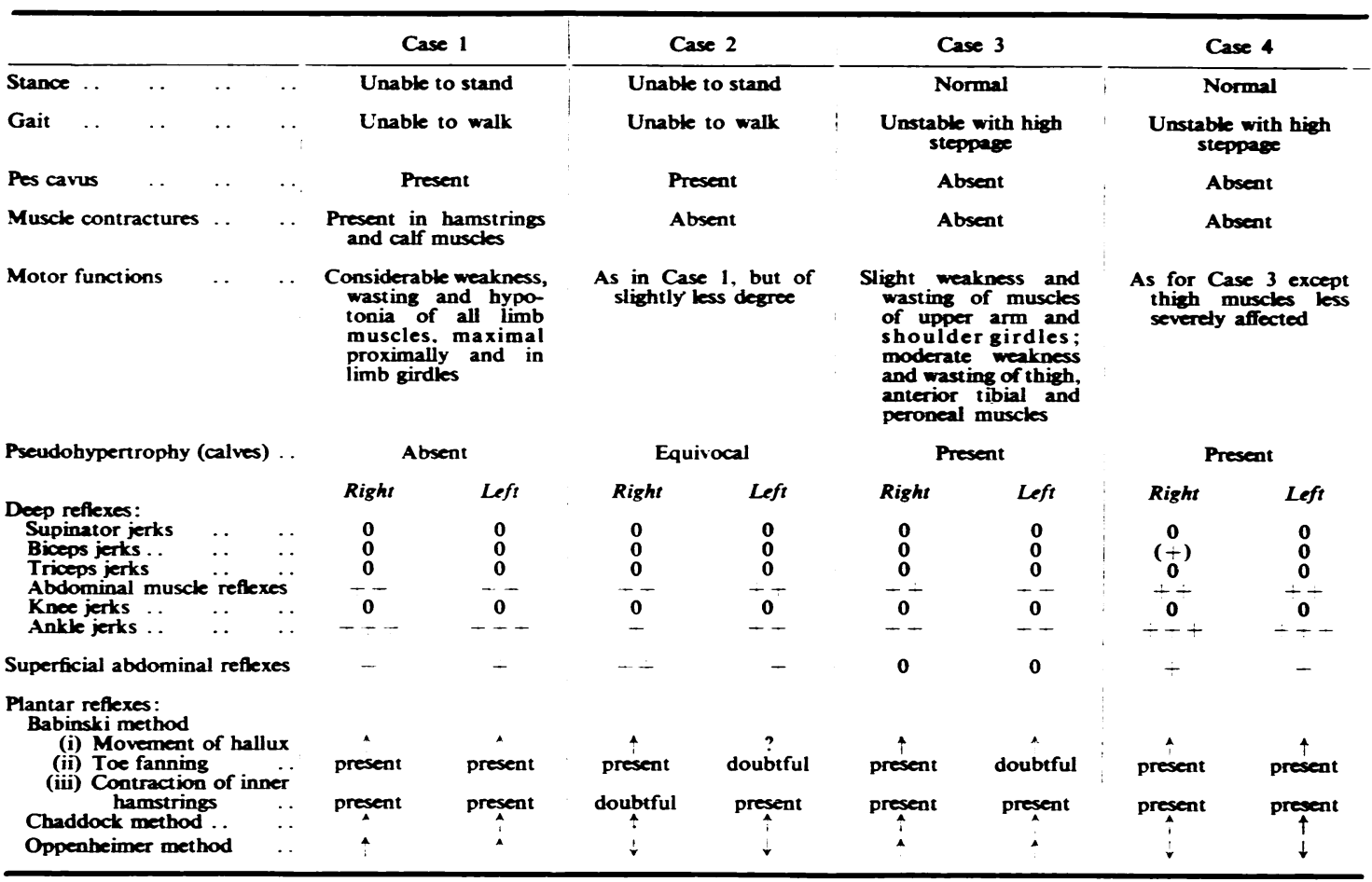

$$
\begin{aligned}
0 & =\text { absent; } \\
(-) & =\text { diminished; } \\
-t o & =\text { normal } \\
i & =\text { plantar fiexion of hallux (fiexor plantar response) } \\
& =\text { dorsifiexion of hallux (extensor plantar response) }
\end{aligned}
$$




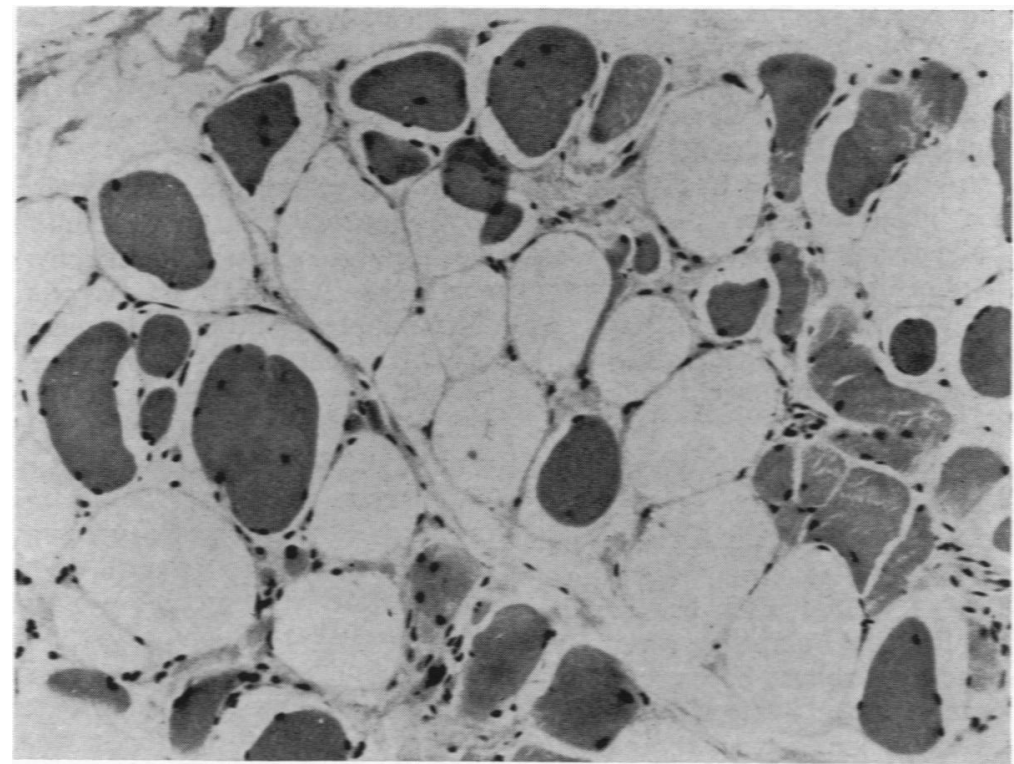

Fig. 2.-Case 4. Transverse section from right gastrocnemius muscle, showing variation in fibre size, degeneration of muscle fibres and infiltration by adipose tissue cells. (Haematoxylin and cosin preparation $\times 150$.)

dystrophy and this sign has been described, the association is uncommon. Thus Bell (1943) in her survey of 1,228 cases of muscular dystrophy drawn from the literature and 113 additional cases from the records of the National Hospital, Queen Square. 1926-1940, mentioned the coexistence of a Babinski sign in only five cases, one of which might well have been an example of Friedreich's ataxia. Shank, Gilder and Hoagland (1944) found no signs of organic disease of the central nervous system in any of their 40 cases of muscular dystrophy. Levison (1951) encountered an extensor plantar response twice in his 192 cases; Tyler and Stephens (1951) and Walton and Nattrass (1954) did not find this sign in any member of their series, numbering 60 and 105 cases respectively. On the other hand, Léri et al. (1923) noted extensor plantar responses in two of their seven cases of muscular dystrophy, while Hassan and Mostafa (1961) reported extensor plantar responses in 11 of 36 cases in Egypt. The latter series included 27 examples of pseudohypertrophic dystrophy, in 10 of whom there were extensor plantar responses: this high incidence led the latter authors to speculate that a racial factor might be responsible for their experience.

Monrad-Krohn (1948) pointed out that an extensor plantar response might occur if the short flexors of the hallux were weaker than the extensors, due to a peripheral paralysis of the former group of muscles. Sicard (1923), in discussing the paper of Léri et al. (1923) cited above, suggested that such a peripheral selective weakness of plantar flexion of the hallux might explain the extensor plantar response in muscular dystrophy, but Léri was able to refute this suggestion as plantar flexion was stronger than dorsiflexion in one of his two cases. Similarly, such peripheral paresis did not occur in our patients, in each of whom we noted that voluntary plantar flexion of the hallux was stronger than voluntary dorsiflexion. Further evidence for the view that the Babinski sign in our patients had its usual significance was supplied by the fact that the Babinski response included fanning of the toes and contraction of the inner hamstrings, and not merely a dorsiflexion of the hallux.

In advanced muscular dystrophy vertebral column deformity may occur and this could conceivably cause spinal cord compression and thus extensor plantar responses. Philip (1886), Kollarits (1906) and Léri et al. (1923) described kyphoscoliosis in cases with muscular dystrophy and extensor plantar responses. However, there was no evidence of significant kyphoscoliosis in our cases so that secondary spinal cord compression was most unlikely.

Some authors (Kollarits, 1906; Léri et al., 1923; Sjövall, 1936; Bell, 1943; Bruce, 1954) have been reluctant to accept an extensor plantar response in muscular dystrophy as evidence of pyramidal tract 
dysfunction, but they have not offered a satisfactory alternative explanation of the significance of this sign. However, Kollarits (1906), in a case of histologically verified familial muscular dystrophy, noted pallor of the pyramidal tracts in his Kultschitzky preparations of the cervical spinal cord, and he published illustrations of these. This patient did have scoliosis, but the author concluded that the pyramidal tract degeneration was primary ('nicht um sekundäre, sondern um primäre Degeneration'). It should be pointed out that Friedreich's ataxia may have been present in other members of the pedigree he described.

If it is accepted that pyramidal tract dysfunction may occur in muscular dystrophy, the combination may be viewed in several ways. It is possible that the association of the two is purely fortuitous, which Crouzon (1911) favoured when he accepted a congenital origin for the Babinski sign in his patient with muscular dystrophy. Secondly, pyramidal tract disorder might be an integral component of the disease called 'muscular dystrophy', although it is not often recognized clinically. This view would deny the purely myogenic nature of muscular dystrophy, and if true one might have expected more pathological evidence of pyramidal tract damage to have accumulated. A third possibility is that certain neurological disorders, particularly familial ones, may tend to have more than a chance association with muscular dystrophy. Philip (1886) recorded 'primary spastic paralysis and pseudohypertrophic paralysis in different members of the same family, with probable heredity in both". In cases of Friedreich's ataxia, Baümlin (1901) and Bing (1905) described the occurrence of pseudohypertrophy of muscles, and Spiller (1910) noted appearances resembling pseudohypertrophy. Bing (1905) regarded the pseudohypertrophy in his case as muscular dystrophy and believed that this was not the mere occurrence of muscular dystrophy with Friedreich's ataxia, but that a close connexion existed between the two diseases. Roth (1948) also referred to a small group of cases suggesting links between Friedreich's ataxia and the myopathies. Biemond (1951) stated that Friedreich's ataxia might be accompanied by progressive muscular dystrophy. Greenfield, Shy, Alvord and Berg (1957) and Stephens, Hoover and Denst (1958), and Tyrer and Sutherland (1961), have recorded histological appearances of muscular dystrophy in patients with varieties of primary spino-cerebellar atrophy. Kollarits (1906) and Sjövall (1936) reported the occurrence of Friedreich's ataxia and muscular dystrophy in different members of the same family, and Kollarits (1906) also noted a similar association between dystrophy and familial spastic paraplegia. van Bogaert (1948) recorded the association of peroneal muscular atrophy and dystrophia myotonia in different members of a family.

An association between one of the primary spino-cerebellar atrophies (familial spastic paraplegia) and muscular dystrophy seems the most reasonable explanation of our four cases of Duchenne-type muscular dystrophy with extensor plantar responses. The presence of pes cavus in two of these patients, and in three of their four affected uncles, tends to support this view, though it must be pointed out that pes cavus was found by Walton and Warrick (1954) in three of 17 cases of uncomplicated Duchenne-type muscular dystrophy.

Previous reports of isolated instances of the combination of muscular dystrophy and primary spino-cerebellar atrophy as cited above, in addition to the family which we record, lend some support for the view that there may be a genetic relation between muscular dystrophy and primary spinocerebellar atrophy. The recognition of this association may be important in clinical diagnosis.

\section{Summary}

A family is reported in which four male siblings with typical pseudohypertrophic muscular dystrophy showed bilateral extensor plantar responses.

The significance of extensor plantar responses in occasional cases of muscular dystrophy is considered. It is suggested that at least in some of the reported cases, and almost certainly in the siblings here recorded, it represents evidence of pyramidal tract disorder. This pyramidal tract disorder may be due to neurological disease coincident with the dystrophy, but in some instances, including our cases, it seems that there may be an association between muscular dystrophy and the primary spino-cerebellar atrophies.

The authors would like to thank Dr. Margaret Mead for her report on the pathology of the muscle biopsy, Miss L. Pegus for drawing the pedigree chart, and Mr. E. W. Hollywood for the photographs.

\section{REFERE.TCES}

Babinski. J. (1896). Sur le réflexe cutané plantaire dans certaines affections organiques du systeme nerveux central. C.R. Soc. Biol. (Paris). 3. 207.

Baümlin. J. (1901). Ueber familiāre Erkrankungen des Nervensystems. Dtsch. Z. Vervenheilk.. 20. 265. Cited by Spiller (1910). Bell. J. (1943). On pseudohy pertrophic and allied types of progressive muscular dystrophy. In The Treasury of Human Inheritance. ed. R. A. Fisher, Vol. 4. part 4. p. 283. Cambridge University Press. Cambridge.

Biemond. A. (1951). Les dégénérations spino-cérébelleuses. Folio psychiat. neerl., 54. 216.

Bing. R. (1905). Eine kombinierte Form der heredofamiliāren Nervenkrankheiten. Disch. Arch. klin. Med., 83. 199. Cited by Spiller (1910). 
Bogaert. L. van (1948). Sur la valeur et la signification de quelques correlations d'hérédo-degénérescences. Encephale. 37, 1.

Brain. W. R. and Wilkinson. M. (1959). Observations on the extensor plantar reflex and its relationship to the functions of the pyramidal tract. Brain, 82. 297.

Bruce. A. N. (ed.) (1954), Neurology, by S. A. Kinnier Wilson. 2nd ed., vol. 2, p. 1111 . Butterworth. London.

Coèrs. C. E. F. and Woolf. A. L. (1959). The Innervation of Muscle. Blackwell. Oxford.

Crouzon. O. (1911). Congrès de médecine. Lyon. Cited by Léri, Girot and Basch (1923)

Greenfield. J. G., Shy, G. M.. Alvord. E. C. and Berg, L. (1957), An Atlas of Muscle Pathology in Neuromuscular Diseases. Livingstone. Edinburgh and London.

Hassan. A. H. and Mostafa, M. M. (1961). Signs of pyramidal tract lesions in Egyotian cases of muscle dystrophy. VIlth International Congress of Neurology, Rome. Excerpta Medica. International Congress Series, No. 38. 162.

Kollarits. J. (1906). Beiträge zur Kenntnis der vererbten Nervenkrankheiten. Dtsch. Z. Nervenheilk.. 30. 293.

Léri. A.. Girot, L. and Basch. G. (1923). L'Extension réflexe des Orteils chez les Myopathiques. Rev. neurol., 30(1), 247.

Levison. H. (1951). Dystroohia Muscularum Progressiva. Acta psychiat. scand., Suppl. 76.

Monrad-Krohn, G. H. (1948). The Clinical Examination of the verious Sistem. 9th ed. Lewis, London.
Philip. R. W. (1886). Primary spastic paralysis and pseudohypertrophic paralysis in different members of the same family. with probable heredity in both. Brain, 8, 520.

Roth, M. (1948). On a possible relationship between hereditary ataxia and peroneal muscular atrophy. ibid., 71. 416.

Shank. R. E. Gilder. H. and Hoagland, C. L. (1944). Studies on diseases of muscle. 1. Progressive muscular dystrophy: a clinical
review of forty cases. A.M.A. Arch. Neurol. Psychiat.. 52. 431 .

Sicard. J. (1923). Discussion on paper by Léri, Girot and Basch (1923). Rev. neurol.. 30, 250.

Sjōvall. B. (1936). Dystrophia Musculorum Progressiva. Acta psychiat. scand.. Suppt. 10.

Spiller. W. G. (1910). Friedreich's ataxia. J. nerv. ment. Dis.. 37. 411.

Stephens. J. Hoover, M. L. and Denst, J. (1958). On familial ataxia, neural amyotrophy, and their association with progressive external ophthalmoplegia. Brain. 81. 556.

Tyler, F. H. and Stephens, F. E. (1951). Studies in disorders of muscle. IV. The clinical manifestations and inheritance of childhood progressive muscular dystrophy. Ann. intern. Med.. 35. 169.

Tyrer, J. H. and Sutherland. J. M. (1961). The primary spinocerebellar atroshies and their associated defects. with a study cerebellar atroshies and their associated

Walton. J. N. and Nattrass, F. J. (1954). On the classification natural history and treatment of the myopathies. ibid.. 77. 169. and Warrick. C. K. (1954). Osseous changes in myopathy. Brit. J. Radiol., 27, 1. 